\title{
Enhancing Wind Power Integration through Optimal Use of Flexibility in Multi-Carrier Energy Systems from the Danish Perspective
}

\author{
Yi Zong1, Awadelrahman M. A. Ahmed'2, Jiawei Wang1, Shi You1, \\ Chresten Træholt ${ }^{1}$, Xianyong Xiao ${ }^{3}$ \\ ${ }^{1}$ Center for Electric Power and Energy, Department of Electrical Engineering, Technical University of Denmark, \\ Roskilde, Denmark \\ ${ }^{2}$ CIRCE-Research Centre for Energy Resources and Consumption, Zaragoza, Spain \\ ${ }^{3}$ College of Electrical Engineering and Information Technology, Sichuan University, Chengdu, China \\ Email: yizo@elektro.dtu.dk
}

How to cite this paper: Zong, Y., Ahmed, A.M.A., Wang, J.W., You, S., Træholt, C. and Xiao, X.Y. (2017) Enhancing Wind Power Integration through Optimal Use of Flexibility in Multi-Carrier Energy Systems from the Danish Perspective. World Journal of Engineering and Technology, 5, 78-88. https://doi.org/10.4236/wjet.2017.54B009

Received: June 27, 2017

Accepted: October 9, 2017

Published: October 12, 2017

\begin{abstract}
Denmark' goal of being independent of fossil energy sources in 2050 puts forward great demands on all energy subsystems (electricity, heat, gas and transport, etc.) to be operated in a holistic manner. The Danish experience and challenges of wind power integration and the development of district heating systems are summarized in this paper. How to optimally use the cross-sectoral flexibility by intelligent control (model predictive control-based) of the key coupling components in an integrated heat and power system including electrical heat pumps in the demand side, and thermal storage applications in buildings is investigated.
\end{abstract}

\section{Keywords}

Cross-Sectoral Flexibility, District Heating Systems, Multi-Carrier

Energy Systems, Power to Heat, Wind Power Integration

\section{Introduction}

As a leading wind power country, Denmark has achieved a record of $42.1 \%$ penetration of wind power in 2015, setting a new world record; and the nation is well on its way to hitting its 2020 energy goals $-50 \%$ of traditional electricity supply must come from wind power [1]. According to Danish government's energy policy, Denmark is striving for complete independence from fossil fuels by 2050. In the electricity and heating sectors, fossil fuel phase-out is expected 
even earlier, and oil burners and coal must be phased out of power plants in Denmark no later than 2030 [2].

Currently, market based power exchange with neighboring countries (such as Norway, Sweden and Germany) has played a major role in integrating Danish wind power, as Denmark can export or import electricity depending on its wind production levels. However, with increasing wind energy integration, more wind power production is sold during times of low or negative electricity prices on the Nord Pool Spot market [3]. In the future, this will happen more frequently and increase the need for balancing resources significantly. Serving the residual demand will be very demanding and costly. The passive consequence is closing down wind turbines in more than 1,000 hours a year unless Denmark chooses an intelligent approach-Smart Energy System solution and various short-term and longer-term storages across the different energy sectors.

Traditionally, the different energy subsystems, i.e., electricity, gas, district heating/cooling and hydrogen had relatively few interactions and were designed and operated independently of each other for the purpose of handling a single energy carrier. However, today, there is significant interest in exploring the synergies between energy networks (e.g. Power to gas energy storage and thermal stores providing demand response). Interactions take place through the conversion of energy between different energy carriers and its storage in order to provide services and ensure that each is operated in an optimal way [4]. A smart energy system is a cost-effective, sustainable and secure energy system in which renewable energy production, infrastructures and consumption are integrated and coordinated through energy services, active users and enabling technologies (see Figure 1). This integration requires more flexibility in the entire energy system while ensuring security of supply, and it will challenge the existing energy (electricity, heat, transportation and gas) infrastructure and its control systems with more complicated dynamics and uncertain problems [5].

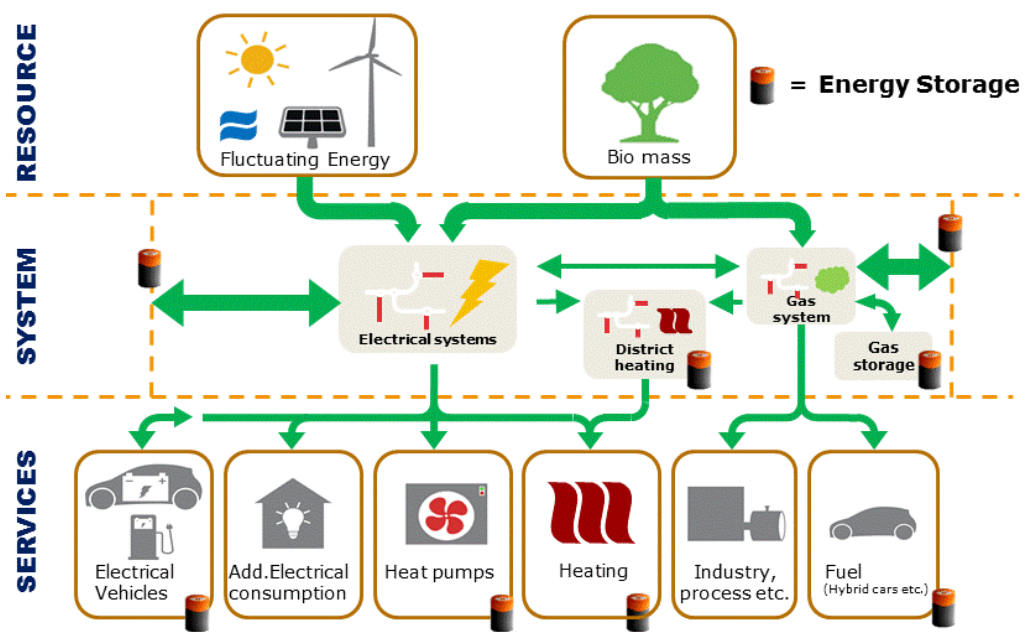

Figure 1. Overview of a future Danish smart energy system [6]. The orange-grey cylinders indicate technologies and subsystems with storage-alike cross-sectoral flexibility options. 
In addition, there are a large number of combined heat and power (CHP) plants in its power system in Denmark. A very large portion of the Danish electricity production is connected to the district heating $(\mathrm{DH})$ system. The strong integration of the electricity and heating sector brings both opportunities and challenges for wind integration. Regulation has been reshaped to reduce heat bound electricity generation in situations with high wind energy feed-in [7]. The DH systems are envisioned to become electricity consumers rather than producers in times of high wind power production for the Danish 2050 energy target, which is known as power-to-heat $(\mathrm{P} 2 \mathrm{H})$ solution.

The goal of our research is to develop optimal control strategies that can coordinate the utilization of the flexibility of the multi-energy system to address various wind power integration issues, such as power balancing and energy storage, etc. The focus will be on the interaction between the different energy sub-systems and the operational flexibility and constraints. This will include relevant dynamic behavior of the networks (i.e. electricity distribution network and district heating network), the key technologies for $\mathrm{P} 2 \mathrm{H}$ (i.e. heat pumps, CHP plants or demand response) and the spatial-temporal variability of and the correlation between the loads of each energy system. The main contribution of this work is to implement a low-complexity Model Predictive Control (MPC)-based optimal control strategy which is used for the low temperature DH systems to deeply harvesting the cross sectoral flexibility in single-family houses.

The remainder of this paper is organized as follows: in Section 2, we present the definition of "flexibility" and the potential flexibility can be provided by buildings/houses that interact with the district heating system in Denmark. How to intelligently control the heating system in buildings is discussed in Section 3. A case study of demand side flexibility for the low temperature district heating is investigated in Section 4. Finally, conclusion and future research are given in Section 5 .

\section{Flexibility and District Heating Systems}

The challenge of integrating a high share of wind power led the Danish institutions and market participants to developing several flexibility options, including the use of interconnectors to other countries, increasing the flexibility of thermal power plants, making district heating more flexible, encouraging system friendly wind power, implementing demand side flexibility as well as introducing alternative options for procuring ancillary services [7] [8].

\subsection{Cross-Sectoral Flexibility}

Flexibility is understood as the ability of a system to respond to variability and uncertainty at different time scales and different locations. In energy system operation and dispatch planning, flexibility is of importance and has a significant commercial value. Options for introducing flexibility into the system are supply side flexibility, thermal storage flexibility, and demand side flexibility [9]. 
Supply side flexibility is historically the dominant option and is relatively simple to manage with base load power sources. However, it is inherently limited by the use of intermittent renewable energy sources (RES), such as wind and solar power.

Buildings are the largest energy consuming sector and account for almost $40 \%$ of society's energy demand in Denmark [10]. The thermal mass of buildings is "for free" and can provide a very large possibility for flexibility. Therefore, buildings play a key role in the green transition and smart buildings can extend beyond the buildings themselves when they act as flexible components in diverse energy systems. To fulfill the 2050 energy target in Denmark, on one hand, buildings need to improve their energy efficiency; on the other hand, thermal capacity of the buildings can be used to become a flexible power consumer that can actively take part in the future energy systems with a high penetration of distributed energy resources (DER). In addition, flexibility at the demand side provides opportunities at the end user level to smooth out the peak demand which will have a major impact on system reliability and generation cost. The buildings as the end users interacting with the different energy carrier systems can provide flexibility such as:

Demand-side flexibility: DER owners who can regulate the generation/demand at their premises are able to offer their flexibility by participating in various demand response/demand-side management. On the demand side, electric boilers, heat pumps, load management by large industrial customers and other flexible consumption units can contribute to balancing the fluctuations of variable RES. The corresponding mechanisms include automated load control by system operators; smart grid and smart metering and various tariff schemes. Although demand-side flexibility is relatively inexpensive, it requires verifiability of demand-side resources, aggregation schemes, and regulatory support etc. [8].

Thermal energy storage-enabled flexibility: The heating, ventilation and air-conditioning system of a building is used to keep the indoor climate within comfortable limits and there are many possibilities to introduce thermal energy storage. Some of the most widely used storage techniques today, such as domestic hot water tanks used together with solar collectors or boilers [11].

\subsection{Modern District Heating Systems in Denmark}

Today, $63 \%$ of heating in private Danish houses is provided by $\mathrm{DH}-$ not only for space heating, but also for hot tap water [12]. DH is playing an important role in the Danish green and efficient integrated energy system. In recent years, around $50 \%$ of heat production is from renewables, with over $95 \%$ share from biomass [13]. Additionally, heat production from electricity, e.g. electric boilers and heat pumps (HP) are increasing. Moreover, the concept of $4^{\text {th }}$ Generation DH (4GDH) is proposed in Denmark, which aims to reduce the heat loss through Low Temperature District Heating (LTDH) technology and increase the renewable energy penetration by acting as flexible loads of power system through CHP plants, HPs, heat storage, etc. 4GDH involves meeting the challenge of more 
energy efficient buildings as well as being an integrated part of the operation of smart energy systems, i.e. integrated smart electricity, gas and thermal grids [14].

In $\mathrm{DH}$, which covers $50 \%$ of the Danish heat demand, HPs are increasingly used in the coming years. This enables higher levels of wind energy to be used for thermal purposes, which contributes to the goal of $100 \%$ district heating to derive from renewable sources by 2035 . HPs connect the electrical and thermal energy systems and increase flexibility in heat production from sustainable sources. On one hand, large heat pumps used in district heating plants can help to integrate excess renewable power into the thermal energy system. Electricity is difficult to store, so heat pumps should be used for thermal purses, when production of electricity is abundant. Other sources of energy for thermal energy production, such as biomass and waste, are easier to store and can therefore be saved to times when less electricity is available and the electricity prices are high. By installing large HPs, the district heating plants help balance the electrical energy system. On the other side, buildings outside the thermal grid can also benefit from heat pumps. Small HPs can be used for individual buildings and larger pumps can supply heat to closely located buildings. By using HPs instead of other individual heating options, local air-pollution is avoided and the quality of life is improved. Moreover, HPs can be integrated with heat recovery and ventilation creating an improved indoor climate [15].

\section{Intelligent Control for Buildings' Heating}

The optimal operation of the district heating system can be obtained by use of intelligent control of the heating system of buildings. The intelligent control makes use of weather forecasts to calculate the need for heating in each room and this information is used to control the operation of the heating system. This is especially relevant for space heating installations, where a weather forecast based control of the inside air temperature can improve the indoor environment. In addition, the efficiency of the heating system improves, as the thermal capacity of the concrete deck may be allowed to discharge before the occurrence of excess solar gain. The peak load for space heating may be reduced by use of higher thermal capacity of the building and by using space heating systems with a peak shaving control system. This may be realized in a simple way by use of a maximum flow controller. Alternatively, an intelligent control system based on 24-h weather forecasts may be used to calculate the required need for space heating and to feed the individual rooms with the predicted energy for heating [14].

In recent years, there are two main research trends in the advanced control for buildings: one is the machine learning based approaches such as fuzzy techniques, genetic algorithms etc.; the other is the model based predictive control (MPC) [16]. The reasons why MPC is an efficient approach to manage the portfolio of energy usage in buildings are [17] [18] [19] [20] [21]:

- can take into account stochastic properties of random disturbance variables (e.g. weather forecast, occupancy profiles); 
- is able to deal with variable energy price that can be easily included into the formulation of an optimization problem;

- can handle minimization of the energy peaks and thus shift energy loads within certain time frame (beneficial because of both the possibility of tariff selection and lowering operational costs);

- can be formulated in a distributed manner and thus the computational load can be split among several optimization solvers;

- can utilize the thermal mass of a building in a better way compared to the conventional control strategies (e.g. Proportional-Integral-Differential (PID), weather compensated or rule based control).

\section{Case Study of Demand Side Flexibility for the Low Temperature District Heating}

Low Temperature District Heating (LTDH) system is defined as a system of district heat supply network and its elements, consumer connections and in-house installations, which can operate in the range between $50^{\circ} \mathrm{C}-55^{\circ} \mathrm{C}$ to $60^{\circ} \mathrm{C}-70^{\circ} \mathrm{C}$ supply and $25^{\circ} \mathrm{C}-30^{\circ} \mathrm{C}$ to $40^{\circ} \mathrm{C}$ return temperatures and meet consumer demands for thermal indoor comfort and domestic hot water [14]. To realize the LTDH concept for the 2050 energy target with $100 \%$ renewables, the network can be developed to be more energy efficient based on the optimal use of integrated buildings' thermal features. A novel heating system that can switch between electrical power and district heating for space heating and domestic hot water in residential buildings is designed at Power Lab DK-PowerFlex houses [22] for the on-going Energy Lab Nordhavn project [23]. It will focus on testing the fuel shift technology (switch between heating sources) with the purpose of providing ancillary services to the electrical grid.

\subsection{System Set-Up}

As shown in Figure 2, the heating system consists of an HP, a stratified hot water tank as thermal energy storage (TES), the hot-water based radiators and the building (PowerFlexHouse3) mass. The DH substation is combined with an HP, where the HP is raising the district heating temperature (e.g. ultralow supply

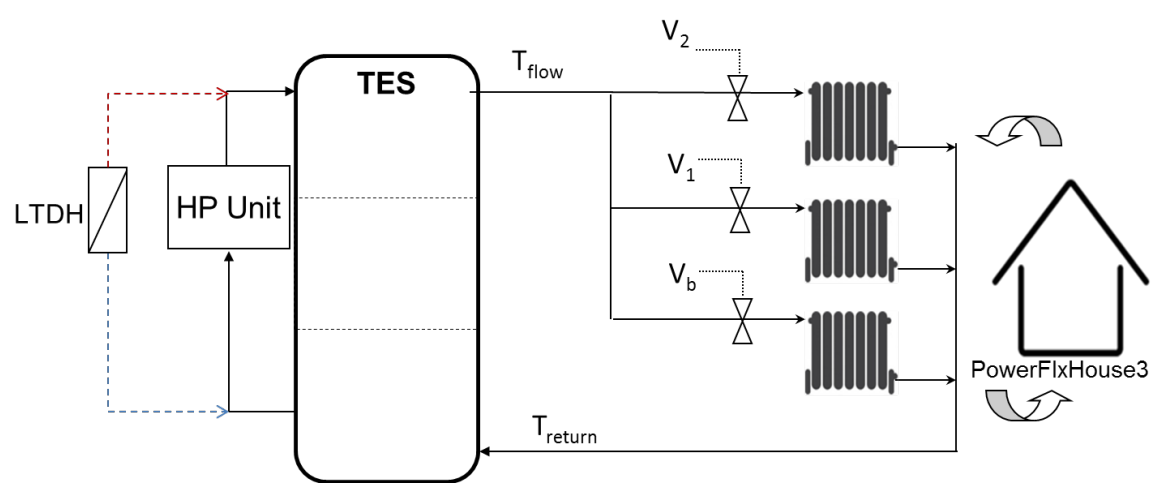

Figure 2. System set-up. 
temperature of $40^{\circ} \mathrm{C}$ ) for the domestic hot water or space heating to a suitable level. The detailed control-oriented models of the individual components in the system can be found in [17] [18].

\subsection{Control Strategy}

In order to utilize both storage capacities, i.e. the building mass and the hot water tank, the MPC-based control strategy which is shown in Figure 3 solves two optimization problems sequentially for every sampling time within the prediction horizon. The PowerFlexHouse3 (PFH3) optimization algorithm determines the hot water radiators' output to supply $\mathrm{PFH} 3$ with the required heat demand. The second optimization algorithm is to optimize the HP electric power consumption to set the tank temperature to the optimal temperature within the operating boundaries.

The objective function of the HP optimization is given by Equation (1):

$$
\min _{P_{e l}} J=\sum_{k=0}^{N-1} C_{k}^{\prime} \times P_{e l k}
$$

$$
\begin{array}{ll}
\text { s.t. } & T_{s, \min , k} \leq g\left(P_{e l}\right) \leq T_{s, \max , k} \quad k=1,2, \ldots,(N-1) \\
& P_{\min } \leq P_{e l} \leq P_{\max }
\end{array}
$$

where $C$ is the electricity price vector for the prediction horizon $N$ sampled every $k$ period of time. $P_{e l}$ is the HP electric power consumption which is the manipulated input within the operational limits $P_{\min }$ and $P_{\max } \mathrm{g}\left(P_{e}\right)$ is a nonlinear function which represents the temperature of the stored water for the each layer in the TES, and it is calculated using the stratified tank model [18]. $T_{s, \min }$ is the minimum stored temperature, in this study the boundary is optimized to meet

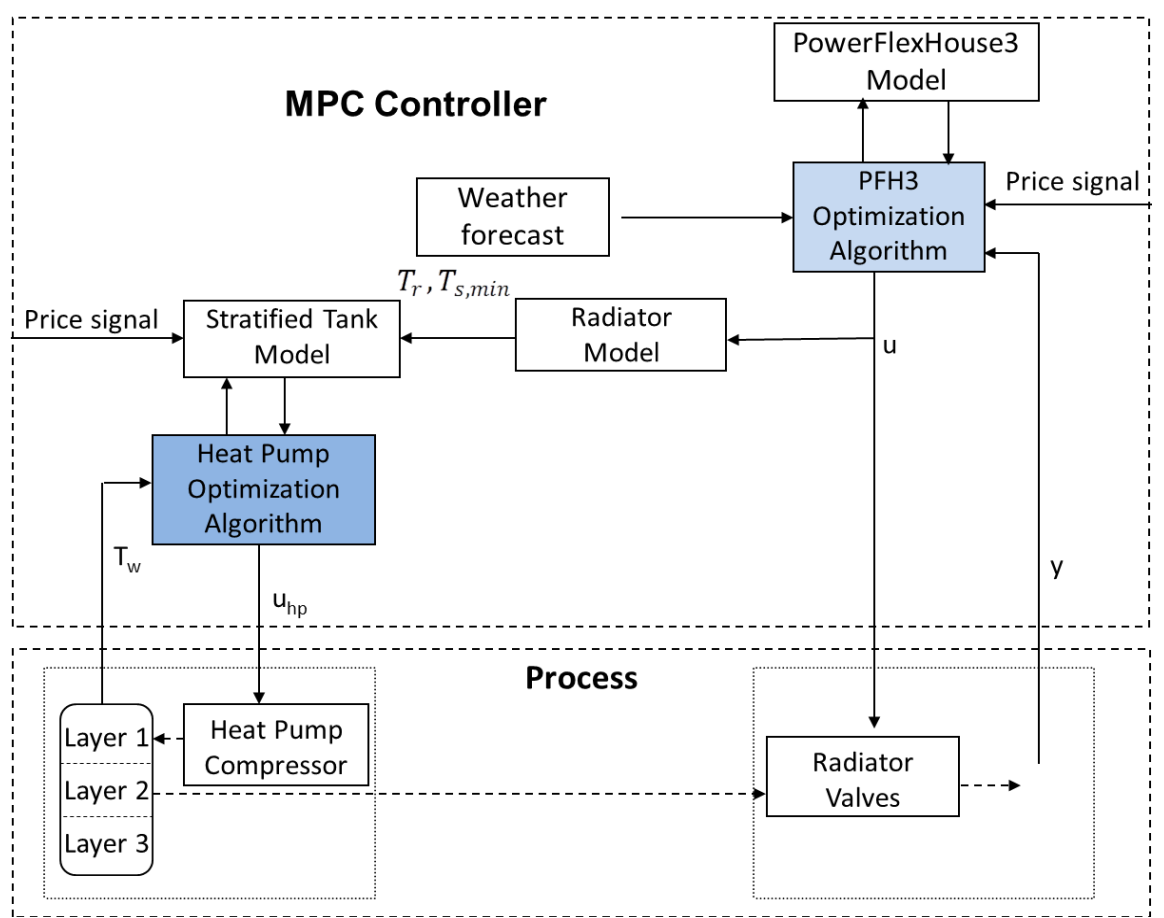

Figure 3. Flowchart of the MPC-based control strategy. 
the demand at a every certain time; this minimum value and it is calculated by utilizing the hot water radiator model in reference [18] to calculate the optimal $T_{s, \min }$ and it should be sufficient to meet the maximum required load in the house. $T_{\mathrm{s}, \max }$ is the maximum boundary and set to $100^{\circ} \mathrm{C}$ temperature to keep the water from being evaporated.

\subsection{Simulation Result}

The system is simulated for 5 days in winter by using day-ahead electricity price signals from the Nord Pool Spot market [24], which has a high negative correlation with the wind power penetration [17] [19]; and weather forecast data is provided by the DTU Wind Division. Figure 4 shows the radiators' optimal power consumption, the dynamic electricity price signal (bottom plot) and indoor temperature (top plot); it is obvious that the radiators consumption is shifted to the low electricity price periods while the indoor temperature is controlled within the comfort constraints (dotted lines). In Figure 5 the bottom plot shows the HP optimal electric power consumption shifted to the low price periods; and the temperature of the top layer in the TES (top plot), the lower red dotted curve is the optimal flow temperature calculated from the optimal heat

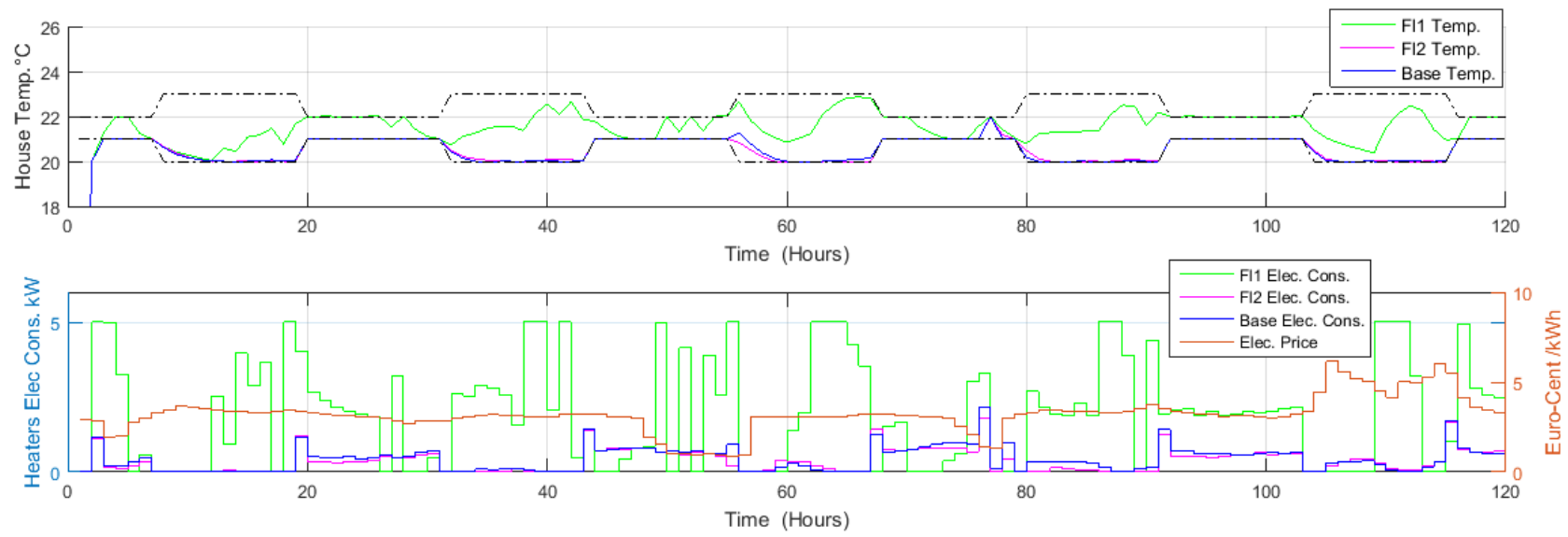

Figure 4. Indoor temperature and optimal heaters' output.
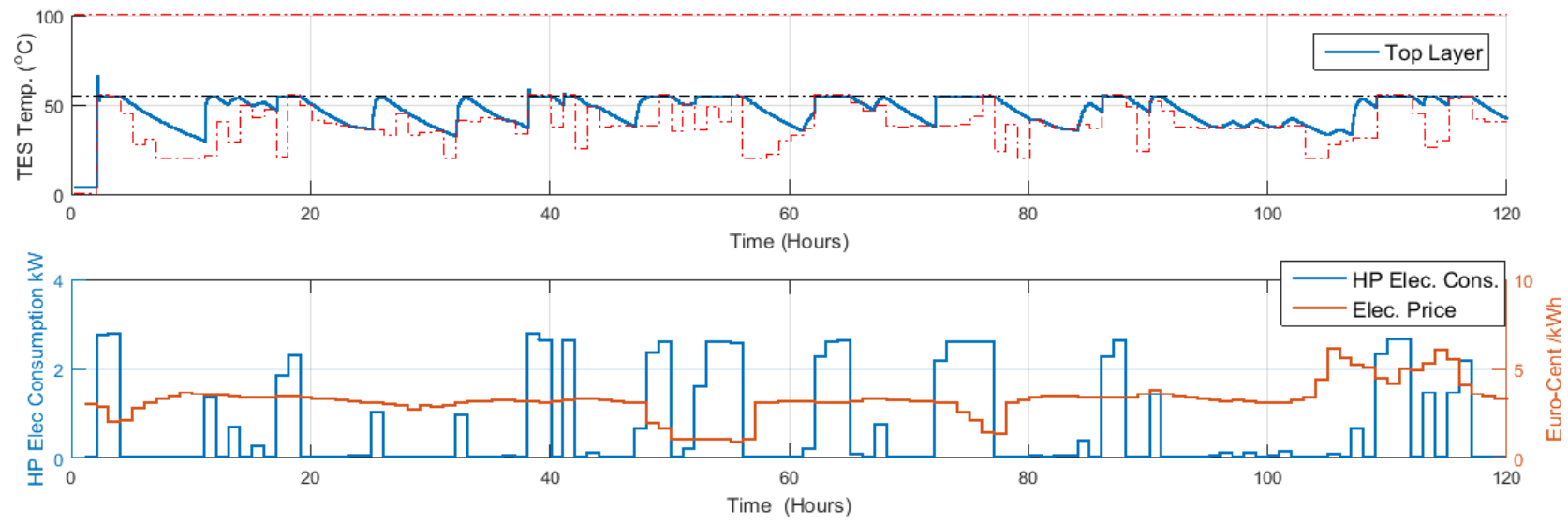

Figure 5. Simulation results for the HP and TES. 
output resulted from PFH3 for every sample time; we can observe that the tank top layer temperature is kept within these varying constraints, even though the maximum temperature in the tank is limited to the HP maximum flow temperature of $55^{\circ} \mathrm{C}$.

Table 1 shows a comparison among the energy costs of three cases: the traditional PI/PID reference case following the lower comfort boundary, the MPC-based control strategy working on the HP and the HP together with TES, connected directly to the PowerFlexHouse3, respectively. The savings are calculated based on the reference case for 10 days simulation [25]. The MPC-based control strategy can achieve shifting the loads intelligently to the low price periods. When using the HP the savings jumped to $73.6 \%$ over the reference case, this significant jump is mainly because of the HP principle of operation and its high energy efficiency. Although, the basic idea of incorporating the hot water tank was to add more flexibility to the system to keep the water temperature in an optimal value between the lower boundary and the upper boundary based on the electricity price, but only $7.9 \%$ more is saved when adding the hot water tank in the system, where the total saving is $81.5 \%$.

\section{Conclusions}

The high penetration of wind power in Denmark has led to changes at all levels of the energy system, including the adaptation of energy markets, intelligent operational control schemes, taxes, the arrangements for new system ancillary services and integration with the heating sector, etc. The Danish experience of wind power integration and district heating technologies show that it is necessary to enhance system flexibility by a deep dive into implementing cross-sectoral flexibility options. The results of the case studies illustrate that buildings play an important role interacting with multi-energy carrier networks by providing demand side flexibility or thermal energy storage-enabled flexibility. The case studies in this paper also show that heat pumps can be considered as a very important element of the future heating supply in Denmark due to their high efficiency and one of the main coupling components for power-to-heat solutions.

The future work will more focus on modeling the key coupling components (CHPs, HPs, electrical boilers, TESs, etc.) on a variety of time scales that not only represent well their operational principles as today but also allow for potential application in an integrated energy system level that can efficiently simulate the interactions across the energy sector under severe uncertainties, and development of the novel optimal operation strategies to manage both the power and

Table 1. Energy savings for different cases based on [18] and [25].

\begin{tabular}{ccc}
\hline Study Cases & Total Electricity Cost in 10 Days (Euro) & Savings \% \\
\hline Reference Case (PI/PID) & $28.00[25]$ & - \\
Case 1: MPC with HP and Buildings & $7.39[18]$ & $73.6 \%$ \\
Case 2: MPC with HP, TES and Buildings & $5.19[18]$ & $81.5 \%$ \\
\hline
\end{tabular}


the heat systems for high penetration of renewables and promoting end-users interaction with the integrated energy systems.

\section{Acknowledgements}

This work is supported by "Cost Effective and Secure Multi-carrier Energy Systems (CESMES)" project grant by the Danish Agency for Science, Technology and Innovation (No. 6144-00037); "Energy Lab Nordhavn-New Urban Energy Infrastructures and Smart Components" project grant by the EUDP (Energy Technology Development and Demonstration Programme) and "Enhancing wind power integration through optimal use of cross-sectoral flexibility in an integrated multi-energy system (EPIMES)" project granted by the Danish Innovation Funding (No. 5185-00005A).

\section{References}

[1] Andersen, A.V. (2016) 42\%: Danish Wind Power Sets World Record. State of Green. http://stateofgreen.com/en/news/42-danish-wind-power-sets-world-record-again

[2] Danish Energy Agency (2012) Energy Policy in Denmark. http://www.cnrec.org.cn/go/AttachmentDownload.aspx?id=\{155faf77-8d72-4ca3-a9 c2-15249ead686f\}

[3] ICIS (2009) Danish Spot Hits Negative Value for First Time. https://www.icis.com/resources/news/2009/12/22/9321337/danish-spot-hits-negativ e-value-for-first-time/

[4] Abeysekera, M., Wu, J. and Jenkins, N. (2016) Integrated Energy System: An Overview of Benefits, Analysis Methods, Research Gaps and Opportunities. http://www.hubnet.org.uk/filebyid/791/InteEnergySystems.pdf

[5] Smart Energy Networks (2015) Vision for Smart Energy in Denmark. http://www.smartenergynetworks.dk/uploads/3/9/5/5/39555879/vision_for_smart_e nergy_in_denmark.pdf

[6] Road Map for Smart Grid Research, Development and Demonstration up to 2020. http://orbit.dtu.dk/files/54874986/prod21368465478030.EN_Smart_Grid_Forskning snetvaerkets_Roadmap_02.05.13.pdf

[7] The Danish Experience with Integrating Variable Renewable Energy https://www.agora-energiewende.de/fileadmin/Projekte/2015/integration-variabler-er neuerbarer-energien-daenemark/Agora_082_Deutsch-Daen_Dialog_final_WEB.pdf

[8] You, S., Lin, J., Zong, Y. and Bindner, H. (2015) The Danish Perspective of Internet of Energy: From Service-Oriented Flexibility Trading to Integrated Design, Planning and Operation of Multiple Cross-Sectoral Energy Systems. China Soc. for Elec. Eng, 35, 3470-3481.

[9] Papaefthymiou, G., Grave, K. and Dragoon, K. (2014) Flexibility Options in Electricity Systems. ECOFYS Germany GmbH, Berlin.

[10] White Papers for a Green Transition: Smart Buildings. http://www.investindk.com/ /media/Files/Reports/Smart\%20Buildings\%20Whitep aper.ashx

[11] Heier, J., Bales, C. and Martin, V. (2015) Combining Thermal Energy Storage with Buildings-A Review. Renewable and Sustainable Energy Reviews, 42, 1305-1325. https://doi.org/10.1016/j.rser.2014.11.031 
[12] District Heating-Danish Experience. https://ens.dk/sites/ens.dk/files/Globalcooperation/dh_danish_experiences180915.p df

[13] Danish Energy Agency, Energistatistik (2015) Technical Report, Danish Ministry of Energy.

[14] Lund, H., Werner, S., Wiltshire, R., et al. (2014) $4^{\text {th }}$ Generation District Heating (4GDH): Integrating Smart Thermal Grids into Future Sustainable Energy Systems. Energy, 68, 1-11. https://doi.org/10.1016/j.energy.2014.02.089

[15] State of Green. Heat pumps. https://stateofgreen.com/en/sectors/heating-cooling/heat-pumps

[16] Cigler, J., Tomáskoa, P. and Siroky, J. (2013) Building LAB: A Tool to Analyze Performance of Model Predictive Controllers for Buildings. Energy and Buildings, 57, 34-41. https://doi.org/10.1016/j.enbuild.2012.10.042

[17] Zong, Y., Böning, G.M. and Santos, R.M. (2016) Challenges of Implementing Economic Model Predictive Control Strategy for Buildings Interacting with Smart Energy Systems. Journal of Applied Thermal Engineering, 114, 1476-1486.

https://doi.org/10.1016/j.applthermaleng.2016.11.141

[18] Awadelrahman, M.A., Zong, Y., Li, H.W. and Agert, C. (2017) Economic Model Predictive Control for Hot Water Based Heating Systems in Smart Building. Journal of Energy and Power Engineering, 9, 112-119.

https://doi.org/10.4236/epe.2017.94B014

[19] Zong, Y., Kullmann, D., Thavlov, A., Gehrke, O. and Bindner, H. (2012) Application of Model Predictive Control for Active Load Management in a Distributed Power System with High Wind Penetration. IEEE Transactions on Smart Grid, 3, 1055-1062. https://doi.org/10.1109/TSG.2011.2177282

[20] Chen, C., et al. (2013) MPC-Based Appliance Scheduling for Residential Building Energy Management Controller. IEEE Transactions on Smart Grid, 4, 1401-1410. https://doi.org/10.1109/TSG.2013.2265239

[21] Lindelöf, D., Afshari, H., et al. (2015) Field Tests of an Adaptive, Model-Predictive Heating Controller for Residential Buildings. Energy and Buildings, 99, 292-302. https://doi.org/10.1016/j.enbuild.2015.04.029

[22] Power Lab DK. http://www.powerlab.dk/Facilities/PowerFlexHouses

[23] EnergyLab Nordhavn Project. http://www.energylabnordhavn.dk/

[24] The Nord Pool Spot Market.

http://www.nordpoolspot.com/Market-data1/Elspot/Area-Prices/SYS1/Hourly/?vie $\mathrm{w}=$ table

[25] Böning, G.M. (2016) Model Predictive Control (MPC)-Based Energy Management of Smart Buildings, in Regenerative Energiesysteme, Fakultät III-Prozesswissenschaften. Technische Universität Berlin. 